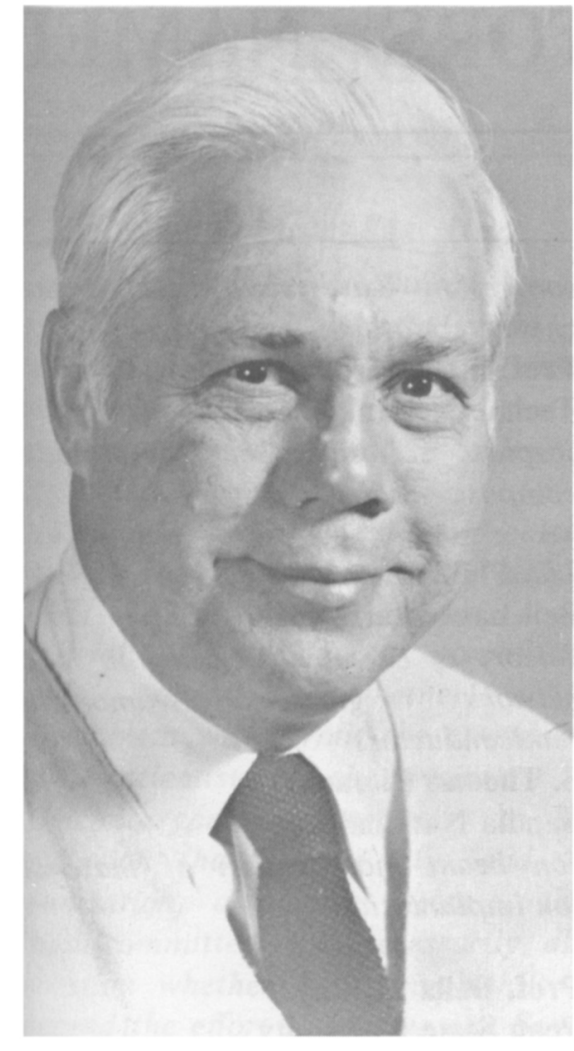

Walter L. Brown

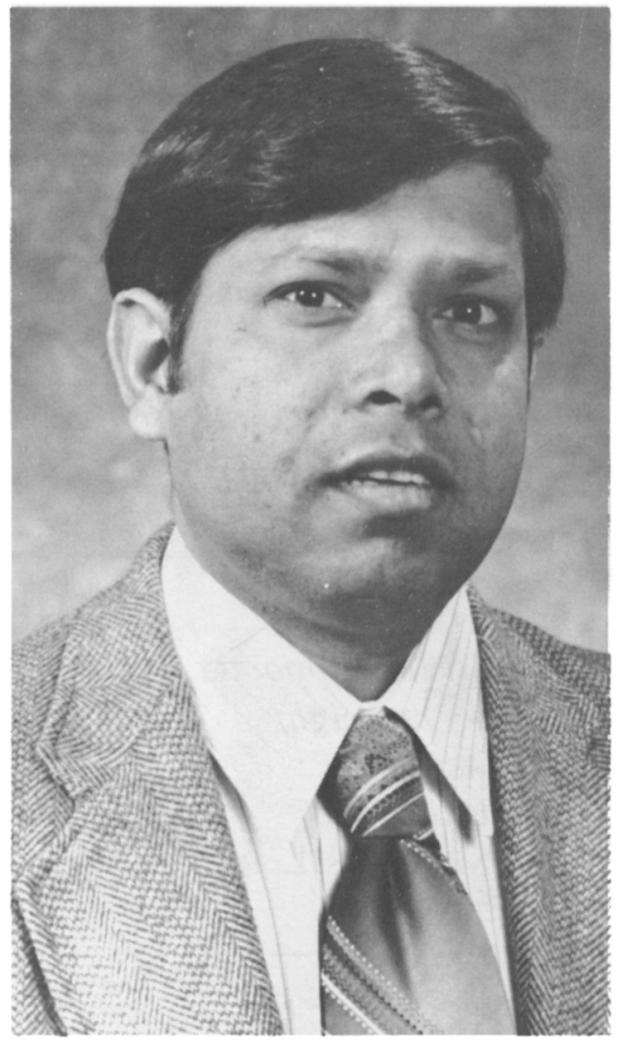

Jagdish Narayan

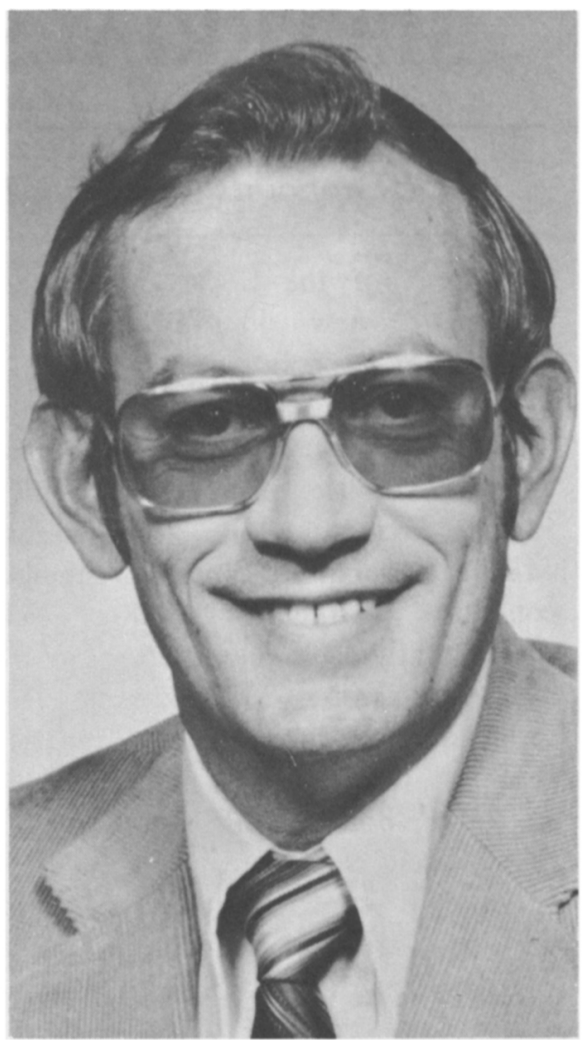

Paul S. Peercy

\title{
1984 BOSTON MEETING CHAIRMEN
}

\section{Brown, Narayan and Peercy to chair next year's meeting}

Three prominent materials scientists, each with an international reputation and each long active in the MRS, have been chosen to organize the 1984 Annual Meeting, to be held in Boston Nov. 26-29. They are Walter L. Brown of Bell Laboratories, Jagdish Narayan of Oak Ridge National Laboratory and Paul S. Peercy of Sandia National Laboratory.

Their principal creative task is to identify the specific topical symposia that will be conducted during the meeting. They welcome suggestions from the membership.

WALTER L. BROWN is the head of the radiation physics research department at Bell Laboratories. He is a fellow of the American Physical Society and a member of Sigma Xi. His principal research interests include semiconductor surfaces, radiation damage in semiconductors, measurements of radiation in space, ion implantation, laser annealing, sputtering by ion beams, and electronically excited desorption processes from insulators. In 1982 he was co-chairman of the MRS symposium on laser-solid interactions and transient thermal processing. $\mathrm{He}$ has given numerous invited talks at MRS meetings and helped organize several other MRS symposia.

JAGDISH NARAYAN is a senior scientist in the solid state division of the Oak Ridge National Laboratory. $\mathrm{He}$ is a fellow of the American Physical Society and has won several awards for his research. His current research interests include defects in semiconductors, laser annealing, radiation damage and the properties of defects in solids. In 1980 he was co- chairman of the MRS symposium on defects in semiconductors and in 1982 served as co-chairman of the MRS meeting on laser-solid interactions and transient thermal processing. He has given numerous invited talks at other MRS symposia, as well.

PAUL S. PEERCY is the manager of the ion implantation and radiation damage research department at Sandia National Laboratories. His principal research interests include high-power pulsed lasers, Raman and Brillouin scattering, phase transitions and tricritical behavior in ferroelectrics, ion implantation of semiconductors and ceramics, ion beam analysis of solids and laser annealing. In 1979 he was a co-chairman of the MRS symposium on laser and electron beam processing of materials. He has given invited talks at several MRS symposia. 